\title{
Atorvastatin prevents glomerular extracellular matrix formation by interfering with the PKC signaling pathway
}

\author{
YAN-HUA XIAO $^{1 *}$, XIAO-YUN HE ${ }^{1,2^{*}}$, QING HAN ${ }^{1}$, FAN YANG $^{1}$ and SU-XIAN ZHOU ${ }^{1}$ \\ ${ }^{1}$ Department of Endocrinology, Affiliated Hospital of Guilin Medical University, Guilin, Guangxi 541001; \\ ${ }^{2}$ Department of Endocrinology, Xiangya Hospital, Central South University, Changsha, Hunan 410078, P.R. China
}

Received April 14, 2017; Accepted January 25, 2018

DOI: $10.3892 / \mathrm{mmr} .2018 .8724$

\begin{abstract}
Platelet-activating factor (PAF) promotes glomerular extracellular matrix (ECM) deposition, primarily through activation of the protein kinase $\mathrm{C}$ (PKC) pathway. The present study was designed to investigate whether atorvastatin, which mediates a protective effect against glomerular ECM deposition and diabetic neuropathy, may interfere with the PKC-transforming growth factor- $\beta 1$ (TGF- $\beta 1$ ) pathway in a model of human mesangial cells (HMCs) exposed to a high glucose (HG) and lysophosphatidylcholine (LPC) environment. HMCs were divided into three treatment groups: Control, high glucose and lysophosphatidylcholine (HG+LPC), and HG+LPC+atorvastatin. Cells were cultured for $24 \mathrm{~h}$. The levels of the ECM-associated molecules collagen IV (Col IV) and fibronectin (Fn) in the supernatant were detected using an ELISA kit. PKC- $\beta 1$, TGF- $\beta 1$ and PAF-receptor gene expression was detected by reverse transcription-quantitative polymerase chain reaction. PKC- $\beta 1$ and TGF- $\beta 1$ protein expression was detected by western blotting, and the subcellular localization of PKC- $\beta 1$ was assessed using immunofluorescence. The results indicated that atorvastatin may reduce the secretion of ECM components (Fn and Col IV) in HMCs in a HG and LPC environment, by inhibiting the increase in PAF secretion and the activation of the PKC-TGF- $\beta 1$ signaling pathway.
\end{abstract}

\section{Introduction}

Diabetic neuropathy (DN) is an important microvascular complication of diabetes. The principal pathological

Correspondence to: Dr Su-Xian Zhou, Department of Endocrinology, Affiliated Hospital of Guilin Medical University, 15 Lequn Road, Xiufeng, Guilin, Guangxi 541001, P.R. China

E-mail: zhousx2017vip@163.com

*Contributed equally

Key words: platelet-activating factor, high glucose and lysophosphatidylcholine, protein kinase C, extracellular matrix, atorvastatin alterations in DN include hypertrophic mesangial cells (MCs), the abnormal deposition of the extracellular matrix (ECM) and renal interstitial fibrosis (1). Fibronectin (Fn) is an important component of the ECM. Fn is primarily synthesized in the early stages of DN and is associated with the local inflammatory reaction of the kidney (2). Collagen IV (Col IV) is one of the major components of the basement membrane. Increased synthesis leads to glomerulosclerosis (3). Additionally, chronic inflammation is associated with abnormal ECM deposition. These alterations are involved in the occurrence and development of DN (4). Platelet-activating factor (PAF) has been reported to be a strong inflammatory factor and may damage renal tissue in a variety of ways (5). A high glucose (HG) and lysophosphatidylcholine (LPC) environment increases the expression of inflammatory cytokines, leading to the stimulation of MCs and endothelial cells to continuously synthesize PAF, ECM and protein kinase C- $\beta 1$ (PKC- $\beta 1)$ (5). PKC is aberrantly activated in the diabetic kidney, which causes an increase in PKC- $\beta 1$ activity and the deposition of ECM proteins, including Fn and Col IV (6).

In addition to their lipid lowering effects, statins may inhibit 3-hydroxy-3-methylglutaryl coenzyme A reductase (7). Studies have reported that atorvastatin may significantly reduce the plasma levels of C-reactive, interleukin (IL)-1 $\beta$, IL-6, tumor necrosis factor- $\alpha$ and other inflammatory markers in patients with Alzheimer's disease (8). Furthermore, statins inhibit HG- and LPC-induced secretion of the ECM (9). These notable effects of statins may be present due to their lipid-lowering and anti-inflammatory actions, in addition to their pleiotropic effects. As a result, statins have been used not only in cardiovascular disease, but for other conditions, including DN (10). However, more evidence in properly designed trials is required to determine whether the protective effect of atorvastatin on the kidney is associated with PAF and PKC- $\beta 1$. In the present study, it was demonstrated that atorvastatin may reduce the secretion of Fn and Col IV in human $(\mathrm{H})$ MCs in a HG and LPC environment, by reducing the increase in PAF secretion via inhibition of PKC-transforming growth factor- $\beta 1$ (TGF- $\beta 1$ ) signaling.

\section{Materials and methods}

Cell culture. Immortalized HMCs (donated by Professor Sun Zilin, Department of Endocrinology, Zhongda Hospital 
affiliated with Southeast University, Nangjing, China) (11), were obtained by double transfection with T-SV40 and H-ras proto-oncogene. These cells retain the basic morphology and biological characteristics of normal human glomerular MCs (12). The cells were maintained in a sterile incubator with $10 \%$ fetal calf serum (Invitrogen; Thermo Fisher Scientific, Inc., Waltham, MA, USA) and Dulbecco's modified Eagle's medium (DMEM; Thermo Fisher Scientific Inc.) in a humidified atmosphere with $5 \% \mathrm{CO}_{2}$ at $37^{\circ} \mathrm{C}$. When cells had reached $90 \%$ confluency, cells were seeded into 6-well plates $\left(6 \times 10^{5}\right.$ cells/well) and then incubated at $37^{\circ} \mathrm{C}$ and $5 \% \mathrm{CO}_{2}$ for $12 \mathrm{~h}$.

Cells were then divided into three groups: A, control $[5.5 \mathrm{mmol} / 1 \mathrm{D}$-glucose (Enzo Life Sciences, Inc., Farmingdale, NY, USA)] (11); B, HG+LPC group [30 mmol/l D-glucose+20 mg/l LPC (Sigma-Aldrich; Merck $\mathrm{KGaA}$, Darmstadt, Germany)]; C, atorvastatin [30 mmol/1 D-glucose $+20 \mathrm{mg} / 1 \mathrm{LPC}+10 \mu \mathrm{mol} / \mathrm{l}$ atorvastatin (Pfizer Inc., New York, NY, USA)]. Group C was pretreated with atorvastatin for $1 \mathrm{~h}$ prior to the addition of $30 \mathrm{mmol} / \mathrm{l} \mathrm{D}$-glucose and $20 \mathrm{mg} / \mathrm{l}$ LPC. Following $\geq 24 \mathrm{~h}$, the supernatant of all three groups was collected and the experiments were repeated three times.

ELISA analysis. The expression levels of Fn, Col IV and PAF in the supernatant of each group was determined by ELISA. Human FN ELISA kit (NeoScientific, Cambridge, MA, USA; cat. no. HF0011), Human Col IV ELISA kit (NeoScientific; cat. no. HC0787), Human PAF ELISA kit (NeoScientific; cat. no. HP0596). The method was performed according to the manufacturer's protocol Each group was set up in three wells in order to repeat the experiment three times.

Detection of PAF receptor (PAF-R), GADPH, PKC- $\beta 1$ and TGF- $\beta 1$ expression in HMCs by reverse transcription-quantitative polymerase chain reaction $(R T-q P C R)$. Total RNA was extracted using TRIzol reagent (Invitrogen; Thermo Fisher Scientific, Inc.), according to the manufacturer's protocol. The RT reaction was performed using the Revert Aid First Strand cDNA Synthesis reagent (Fermentas; Thermo Fisher Scientific, Inc.) at $42^{\circ} \mathrm{C}$ for $15 \mathrm{~min}$ and $95^{\circ} \mathrm{C}$ for $3 \mathrm{~min}$, followed by $4^{\circ} \mathrm{C}$ for $5 \mathrm{~min}$; according to the manufacturer's protocol. PAF-R primer sequences were as follows: Forward, 5'-TGCCCCTGC TACAGGCACCA-3' and reverse, 5'-TGCTGTAAACAATCG GGAAGAG-3'. GAPDH primers sequences were as follows: Forward, 5'-ACACCCACTCCTCCACCTTT-3' and reverse, 5'-TTACTCCTTGGAGGCCATGT-3'.

PKC- $\beta 1$ primer sequences were as follows: Forward, 5'-GGGGGCGACCTCATGTAT-3' and reverse, 5'-GCAATT TCTGCAGCGTAAAA- 3 '. TGF- $\beta 1$ primer sequences were as follows: Forward, 5'-ACTACTACGCCAAGGAGGTCA C-3' and reverse, 5'-TGCTTGAACTTGTCATAGATTTCG-3'. Primers were designed using Premier Oligo 5 and Primer 6.22 software (Premier Biosoft International, Palo Alto, CA, USA). qPCR assays were performed using a QuantStudio 5 Real-Time PCR System (Thermo Fisher Scientific, Inc.) in a $20 \mu \mathrm{l}$ PCR volume using iQ SyBr Green Supermix for $10 \mathrm{sec}$ at $95^{\circ} \mathrm{C}$, followed by 40 cycles of $56^{\circ} \mathrm{C}$ for $20 \mathrm{sec}$ and $72^{\circ} \mathrm{C}$ for $10 \mathrm{sec}$. The quantification cycle $\left(2^{-\Delta \Delta \mathrm{C} q}\right)$ method was used to calculate the relative changes in expression levels (13). Each sample was prepared in triplicate, and the results are expressed as the mean of three independent experiments.

Western blotting. The cells were lysed using a HMC lysis buffer (Promega Corporation, Madison, WI, USA). Lysates were transferred into an Eppendorf tube and centrifuged at $12,000 \mathrm{x} \mathrm{g}$ for $15 \mathrm{~min}$ at $4^{\circ} \mathrm{C}$. The supernatant was collected, and the concentration of protein was determined by ultraviolet spectroscopy (14). Protein $(50 \mu \mathrm{g})$ were separated by 5\% SDS-PAGE (Bio-Rad Laboratories Inc., Hercules, CA, USA) and transferred onto a nitrocellulose membrane (Bio-Rad Laboratories, Inc.). The membrane was incubated in TBS with $0.1 \%$ Tween-20 (TBST) and 5\% fat-free milk for $1 \mathrm{~h}$ at $37^{\circ} \mathrm{C}$. The proteins were detected with the addition of primary antibodies which were left to incubate overnight at $4^{\circ} \mathrm{C}$ (Sigma-Aldrich; Merck KGaA). The dilution ratios were as follows: TGF- $\beta 1$ (Santa Cruz Biotechnology, Inc., Dallas, TX, USA; cat. no. SC-130348; 1:2,000); PKC- $\beta 1$ (Santa Cruz Biotechnology, Inc.; cat. no. SC-8393; 1:400) and GAPDH (Santa Cruz Biotechnology, Inc.; cat. no. SC-32233; 1:3,000). Following washing with TBST, membranes were incubated with horseradish peroxidase-conjugated secondary antibodies (Santa Cruz Biotechnology, Inc.; cat. no. SC-516245; 1:5,000) for $1 \mathrm{~h}$ at $4^{\circ} \mathrm{C}$, followed by additional washes with TBST. Protein bands were visualized by enhanced chemiluminescence (Pierce; Thermo Fisher Scientific, Inc.). The Scion Image 4.03 system (National Institutes of Health, Bethesda, MD, USA) was used to quantify band intensity, and results are expressed as the mean of three independent experiments.

Antibodies, immunoprecipitation and immunoblotting. Cells $\left(2 \times 10^{4}\right.$ cells $\left./ \mathrm{ml}\right)$ were cultured on coverslips in $24-w e l l$ plates and serum-starved for $24 \mathrm{~h}$. The cells were subsequently fixed with $4 \%$ paraformaldehyde for $5 \mathrm{~min}$ at $-20^{\circ} \mathrm{C}$ and blocked for $30 \mathrm{~min}$ in $0.2 \%$ Triton X-100 in PBS. The cells were incubated with aforementioned primary antibodies $(1: 50)$ overnight at $4^{\circ} \mathrm{C}$, followed by fluorescein isothiocyanate-conjugated secondary anti-mouse IgG antibodies (Dako; Agilent Technologies, Inc., Santa Clara, CA, USA) for $1 \mathrm{~h}$ in the dark at room temperature. Following three washes in PBS, coverslips were placed on slides and visualized by confocal microscopy (magnification, $\mathrm{x} 400$ ). Fluorescence intensity was analyzed using Image J software (version 1.48; National Institutes of Health).

Statistical analysis. All data are presented as the mean \pm standard deviation. Data was analyzed using SPSS 18.0 software (SPSS, Inc., Chicago, IL, USA) for Windows. Multigroup comparisons of the means were performed using one-way analysis of variance test followed by the Newman-Keuls post hoc test. Differences between two groups were assessed by Student's t-test. $\alpha=0.05$ and $\mathrm{P}<0.05$ was considered to indicate a statistically significant difference.

\section{Results}

Atorvastatin inhibits the expression of Fn and Col IV in HMCs. Levels of Fn and Col IV in the supernatant of the HG+LPC group were significantly higher compared with the control group $(\mathrm{P}<0.05)$. In the presence of atorvastatin their levels were significantly decreased (Table I; Figs. 1 and 2). 
Table I. Effects of atorvastatin on Fn (mg/l) and Col IV $(\mu \mathrm{g} / \mathrm{l})$ in human mesangial cells.

\begin{tabular}{lcc}
\hline Group & Fn $(\mathrm{mg} / \mathrm{l})$ & Col IV $(\mu \mathrm{g} / \mathrm{l})$ \\
\hline Control & $3.90 \pm 0.43$ & $4.54 \pm 0.74$ \\
HG+LPC & $7.89 \pm 0.34^{\mathrm{a}}$ & $16.32 \pm 1.55^{\mathrm{a}}$ \\
HG+LPC+atorvastatin & $5.17 \pm 0.34^{\mathrm{b}}$ & $10.80 \pm 1.70^{\mathrm{b}}$ \\
\hline
\end{tabular}

${ }^{\mathrm{a}} \mathrm{P}<0.05$ vs. control group; ${ }^{\mathrm{b}} \mathrm{P}<0.05$ vs. HG+LPC group. Each group was cultured for $24 \mathrm{~h}$ and the experiment was repeated three times. Fn and Col IV levels in cell culture supernatants were detected by ELISA. Fn, fibronectin; Col IV, collagen IV; HG, high glucose; LPC, lysophosphatidylcholine.

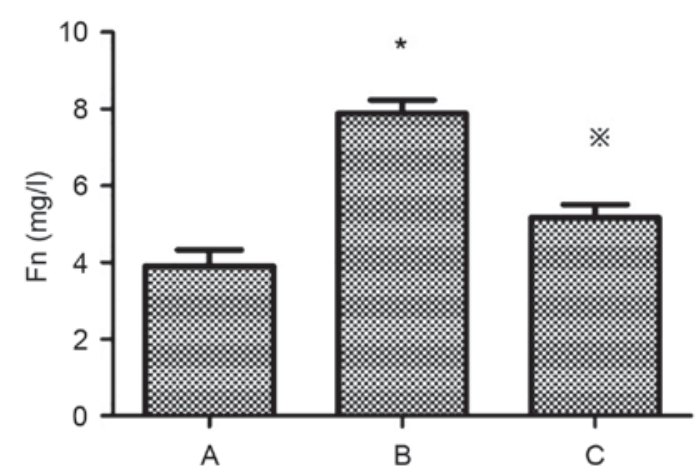

Figure 1. Effects of atorvastatin on Fn (mg/l) in human mesangial cells. The level of Fn in each group was detected by ELISA. Group A, control $(5.5 \mathrm{mmol} / 1$ D-glucose); Group B, HG+LPC group (30 mmol/1 D-glucose+20 mg/l LPC); Group C, atorvastatin group (30 mmol/1 D-glucose+20 mg/l LPC+10 $\mu \mathrm{mol} / 1$ atorvastatin). Data represents the mean \pm standard deviation of three independent experiments. ${ }^{*} \mathrm{P}<0.05$ vs. group $\mathrm{A} ;{ }^{*} \mathrm{P}<0.05$ vs. group $\mathrm{B}$. Fn, fibronectin HG, high glucose; LPC, lysophosphatidylcholine.

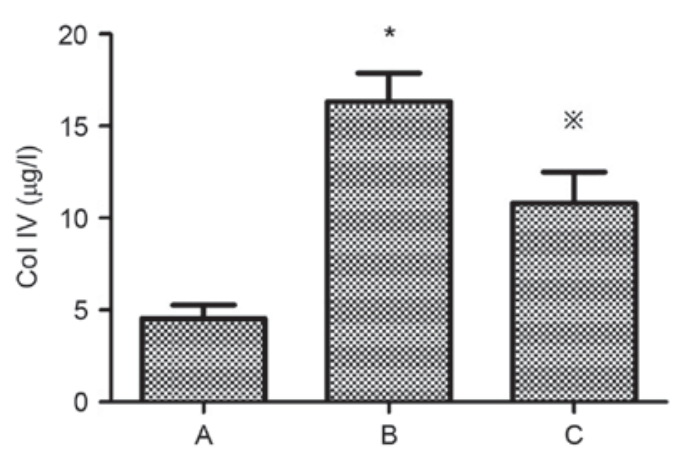

Figure 2. Effects of atorvastatin on Col IV $(\mu \mathrm{g} / \mathrm{l})$ in human mesangial cells. The level of Col IV in each group was detected by ELISA. Group A,control $(5.5 \mathrm{mmol} / 1$ D-glucose); Group B, HG+LPC group (30 mmol/1 D-glucose+20 mg/l LPC); Group C, atorvastatin group (30 mmol/1 D-glucose+20 mg/l LPC+10 $\mu \mathrm{mol} / 1$ atorvastatin). Data represents the mean \pm standard error of three independent experiments. ${ }^{*} \mathrm{P}<0.05$ vs. group $\mathrm{A} ;{ }^{*} \mathrm{P}<0.05$ vs. group B. Col IV, collagen IV; $\mathrm{HG}$, high glucose; LPC, lysophosphatidylcholine.

Atorvastatin inhibits the expression of PAF and PAF-R $m R N A$ in HMCs. Compared with the control group, the expression of PAF and PAF-R mRNA was significantly higher in the HG+LPC group $(\mathrm{P}<0.05)$. Atorvastatin inhibited the increase in PAF content in the supernatant of HMCs $(\mathrm{P}<0.05)$ (Table II;

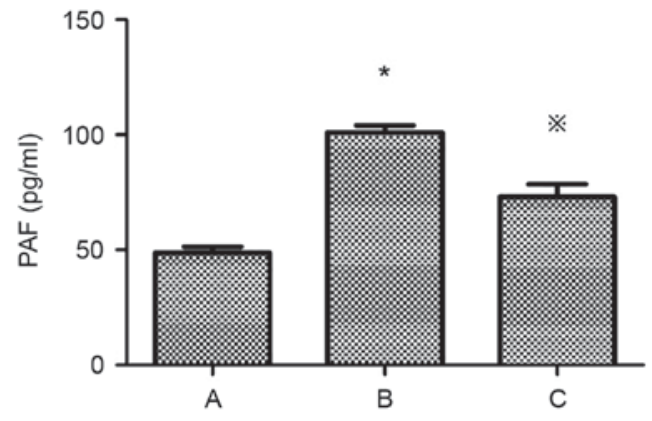

Figure 3. Effects of atorvastatin on PAF $(\mathrm{pg} / \mathrm{ml})$ in human mesangial cells. The level of PAF in each group was detected by ELISA. Group A, control (5.5 mmol/1 D-glucose); Group B, HG+LPC group (30 mmol/1 D-glucose $+20 \mathrm{mg} / 1 \mathrm{LPC}$ ); Group C, atorvastatin group (30 mmol/1 D-glucose $+20 \mathrm{mg} / 1 \mathrm{LPC}+10 \mu \mathrm{mol} / 1$ atorvastatin). Data represents the mean \pm standard error of three independent experiments. ${ }^{*} \mathrm{P}<0.05$ vs. group $\mathrm{A}$; ${ }^{\star} \mathrm{P}<0.05$ vs. group B. PAF, platelet-activating factor; HG, high glucose; LPC, lysophosphatidylcholine.

Fig. 3), in addition to the expression of the PAF-R mRNA gene in the HG+LPC environment ( $\mathrm{P}<0.05$; Table II; Fig. 4).

Atorvastatin inhibits the expression of TGF- $\beta 1$ in HMCs. TGF- $\beta 1$ expression is upregulated in HMCs in the presence of PAF, HG and LPC. TGF- $\beta 1$ mRNA (Table III; Fig. 5) and protein (Fig. 6) expression levels were increased in HMCs treated with $\mathrm{HG}+\mathrm{LPC}$ relative to the control $(\mathrm{P}<0.05)$. Expression was significantly lower in cells treated with atorvastatin compared with those treated with HG+LPC only $(\mathrm{P}<0.05)$.

Atorvastatin inhibits the expression of PKC- $\beta 1$ in HMCs. Detection of PKC- $\beta 1 \mathrm{mRNA}$ expression in HMCs in each group by RT-qPCR revealed that mRNA levels were significantly higher in the HG+LPC group compared with the control $(\mathrm{P}<0.05)$. The expression was significantly higher in the HG+LPC group compared with cells treated with HG+LPC+atorvastatin $(\mathrm{P}<0.05)$. Thus, atorvastatin may inhibit the expression of PKC- $\beta 1$ mRNA in HMCs (Table IV; Fig. 7).

Detection of PKC- $\beta 1$ protein expression in HMCs in each group by western blotting. PKC- $\beta 1$ protein (Fig. 8) expression levels were significantly increased in HMCs treated with HG+LPC relative to the control $(\mathrm{P}<0.05)$. Expression levels were significantly lower in cells treated with atorvastatin compared with those treated with HG+LPC only $(\mathrm{P}<0.05)$.

Effect of atorvastatin on the expression and localization of $P K C-\beta 1$ in HMCs. In control cells, PKC- $\beta 1$ immunofluorescence was diffusely distributed throughout the cytoplasm, with no membrane or nuclear localization. Treatment with HG and LPC increased PKC- $\beta 1$ protein expression levels, and induced the translocation of the protein from the cytoplasm to the nucleus. These effects were reduced in cells treated with atorvastatin (Fig. 9).

Mean fluorescence intensity of PKC- $\beta 1$ in HMCs under various treatment conditions. The mean fluorescence intensity of PKC- $\beta 1$ in HMCs was significantly increased 
Table II. Effects of atorvastatin on the expression of PAF and PAF-R mRNA gene in human mesangial cells.

\begin{tabular}{lcc}
\hline Group & PAF $(\mathrm{pg} / \mathrm{ml})$ & $\begin{array}{c}\text { PAF-R } \\
\text { mRNA expression }\end{array}$ \\
\hline Control & $48.72 \pm 2.55$ & $1.0 \pm 0$ \\
HG+LPC & $101.1 \pm 3.00^{\mathrm{a}}$ & $2.48 \pm 0.18^{\mathrm{a}}$ \\
HG+LPC+atorvastatin & $73.03 \pm 5.55^{\mathrm{b}}$ & $1.01 \pm 0.11^{\mathrm{b}}$ \\
\hline
\end{tabular}

${ }^{\mathrm{a}} \mathrm{P}<0.05$ vs. control group; ${ }^{\mathrm{b}} \mathrm{P}<0.05$ vs. $\mathrm{HG}+\mathrm{LPC}$ group. Each group was cultured for $24 \mathrm{~h}$ and the experiment was repeated three times. The level of PAF in each group was detected by ELISA. Detection of PAF-R gene expression in mesangial cells was by reverse transcription-quantitative polymerase chain reaction. PAF, platelet-activating factor; PAF-R, platelet-activating factor-receptor; HG, high glucose; LPC, lysophosphatidylcholine.

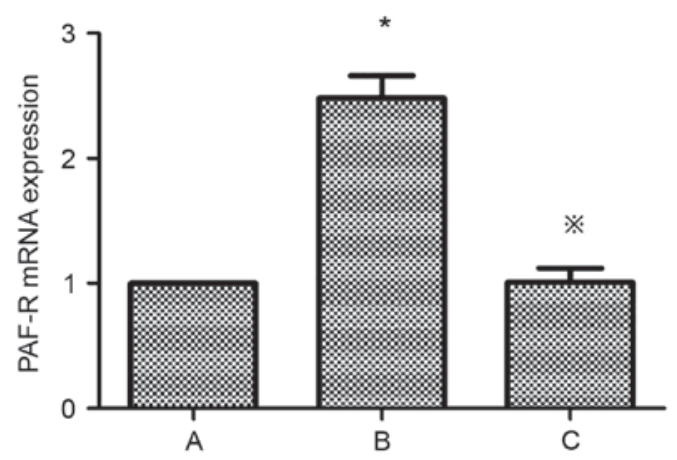

Figure 4. Effects of atorvastatin on PAF-R mRNA expression in HMCs. Detection of PAF-R gene expression in HMCs was detected by reverse transcription-quantitative polymerase chain reaction. Group A, control (5.5 mmol/1 D-glucose); Group B, HG+LPC group (30 mmol/1 D-glucose+20 mg/1 LPC); Group C, atorvastatin group (30 mmol/1 D-glucose $+20 \mathrm{mg} / 1 \mathrm{LPC}+10 \mu \mathrm{mol} / 1$ atorvastatin). Data represents the mean \pm standard error of three independent experiments. $\mathrm{P}<0.05$ vs. group $\mathrm{A} ;{ }^{*} \mathrm{P}<0.05$ vs. group B. PAF-R, platelet-activating factor-receptor; HMCs, human mesangial cells; HG, high glucose; LPC, lysophosphatidylcholine.

in the HG+LPC group compared with the control $(\mathrm{P}<0.05)$. The addition of atorvastatin to the HG+LPC environment significantly reduced the mean fluorescence intensity $(\mathrm{P}<0.05$; Table V; Fig. 10).

\section{Discussion}

Statins have the potential to be used to treat DN. This disease is thought to be triggered by abnormal ECM deposition and a decrease in the glomerular filtration rate. Morphometric studies on HMCs in a HG environment provide convincing evidence that Col IV and Fn are increased, which partially explains the occurrence of glomerular sclerosis and renal failure $(15,16)$. Genetic and environmental factors contribute to renal failure. For example, patients with diabetes may have increased concentrations of PAF, a potent pro-inflammatory factor implicated in the pathogenesis of DN (17). Under certain stimuli, various cell types may secrete PAF, including platelets, endothelial cells and MCs (18). The primary source of PAF, however, is the kidney, in which $20-25 \%$ of PAF is
Table III. Effects of atorvastatin on the expression of TGF- $\beta 1$ mRNA gene human mesangial cells.

\begin{tabular}{lc} 
Group & TGF- $\beta 1$ mRNA expression level \\
\hline Control & $1 \pm 0$ \\
HG+LPC & $1.88 \pm 0.21^{\mathrm{a}}$ \\
HG+LPC+atorvastatin & $1.43 \pm 0.22^{\mathrm{b}}$ \\
\hline
\end{tabular}

${ }^{\mathrm{a}} \mathrm{P}<0.05$ vs. control group; ${ }^{\mathrm{b}} \mathrm{P}<0.05$ vs. $\mathrm{HG}+\mathrm{LPC}$ group. Each group was cultured for $24 \mathrm{~h}$ and the experiment was repeated three times. Detection of TGF- $\beta 1 \mathrm{mRNA}$ expression was by reverse transcription-quantitative polymerase chain reaction. TGF- $\beta 1$, transforming growth factor- $\beta 1$; HG, high glucose; LPC, lysophosphatidylcholine.

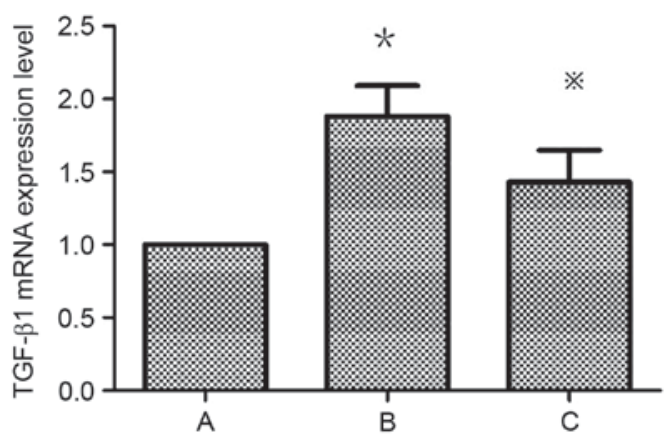

Figure 5. TGF- $\beta 1$ mRNA expression in human mesangial cells under various treatment conditions. Expression levels were determined relative to that of GAPDH by reverse transcription-quantitative polymerase chain reaction. Group A, control (5.5 mmol/1 D-glucose); Group B, HG+LPC group (30 mmol/1 D-glucose+20 mg/l LPC); Group C, atorvastatin group (30 mmol/1 D-glucose $+20 \mathrm{mg} / 1 \mathrm{LPC}+10 \mu \mathrm{mol} / 1$ atorvastatin). Data represents the mean \pm standard error of three independent experiments. ${ }^{*} \mathrm{P}<0.05$ vs. group $\mathrm{A} ;{ }^{*} \mathrm{P}<0.05$ vs. group $\mathrm{B}$. TGF- $\beta 1$, transforming growth factor- $\beta 1$; HG, high glucose; LPC, lysophosphatidylcholine.
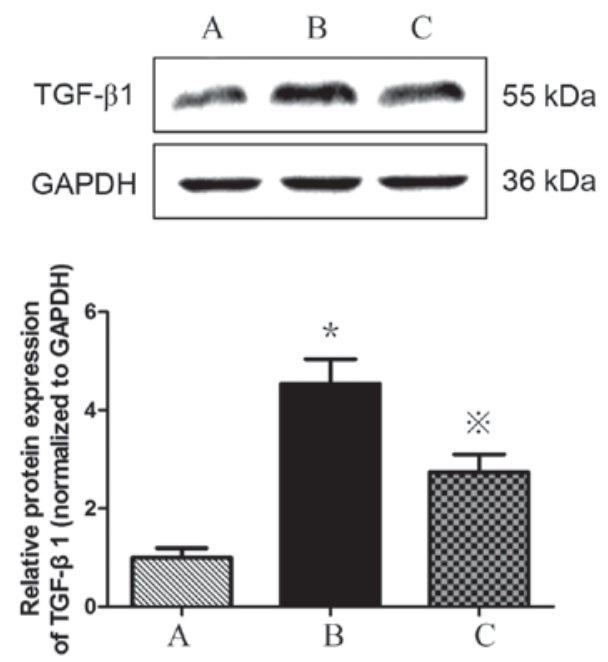

Figure 6. TGF- $\beta 1$ protein expression in human mesangial cells under various treatment conditions. Protein expression levels were determined by western blotting, with GAPDH used as a loading control. Group A, control; Group B, HG+LPC; Group C, HG+LPC+atorvastatin. Data represents the mean \pm standard error of three independent experiments. ${ }^{*} \mathrm{P}<0.05$ vs. group $\mathrm{A},{ }^{*} \mathrm{P}<0.05$ vs. group $\mathrm{B}$. TGF- $\beta 1$, transforming growth factor- $\beta 1$; $\mathrm{HG}$, high glucose; LPC, lysophosphatidylcholine. 
Table IV. PKC- $\beta 1$ mRNA expression in each group $\left(2^{-\Delta \Delta C q}\right)$.

\begin{tabular}{lc}
\hline Group & PKC- $\beta 1$ mRNA expression level \\
\hline Control & $1 \pm 0$ \\
HG+LPC & $2.12 \pm 0.31^{\mathrm{a}}$ \\
HG+LPC+atorvastatin & $1.02 \pm 0.001^{\mathrm{b}}$
\end{tabular}

${ }^{\mathrm{a}} \mathrm{P}<0.05$ vs. control group; ${ }^{\mathrm{b}} \mathrm{P}<0.05$ vs. $\mathrm{HG}+\mathrm{LPC}$ group. Each group was cultured for $24 \mathrm{~h}$ and the experiment was repeated three times. Detection of PKC- $\beta 1 \mathrm{mRNA}$ expression in human mesangial cells was by reverse transcription-quantitative polymerase chain reaction. PKC- $\beta 1$, protein kinase $\mathrm{C}-\beta 1$; $\mathrm{HG}$, high glucose; LPC, lysophosphatidylcholine.

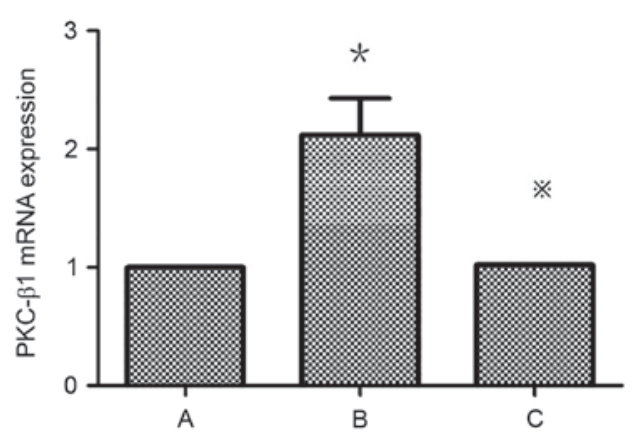

Figure 7. PKC- $\beta 1$ mRNA expression in human mesangial cells under various treatment conditions. Expression levels were determined relative to that of GAPDH by reverse transcription-quantitative polymerase chain reaction. Group A, control $(5.5 \mathrm{mmol} / 1 \mathrm{D}$-glucose; Group B, HG+LPC group (30 mmol/1 D-glucose+20 mg/1 LPC); Group C, atorvastatin group $(30 \mathrm{mmol} / 1 \mathrm{D}$-glucose $+20 \mathrm{mg} / 1 \mathrm{LPC}+10 \mu \mathrm{mol} / 1$ atorvastatin. Data represents the mean \pm standard error of three independent experiments. ${ }^{*} \mathrm{P}<0.05$ vs. group $\mathrm{A},{ }^{{ }^{*}} \mathrm{P}<0.05$ vs. group $\mathrm{B}$. PKC- $\beta 1$, protein kinase $\mathrm{C}-\beta 1$; $\mathrm{HG}$, high glucose; LPC, lysophosphatidylcholine.

secreted by MCs (19). MCs are the principal component of the glomerular filtration barrier and excessive expression of PAF may cause damage to this interface. A previous study reported that PAF is able to promote the secretion of the ECM (20). Excessive secretion of ECM deposition in MCs results in the development of glomerular sclerosis (20). The PAF-R is a $G$ protein coupled receptor that is expressed on MCs. The binding of PAF triggers downstream signaling pathways resulting in the production of effector molecules, including arachidonic acid, prostacyclin and TGF- $\beta 1$ which, in turn, regulate ECM secretion $(5,21)$. The expression of PAF-R mRNA has been detected in all cells of the kidney, and its levels depend on the amount of PAF present. In a model of unilateral ureteral obstruction, PAF-R expression increased by 70 -fold (22), revealing that an inflammatory environment may stimulate the kidney to secrete PAF, and the increase in PAF secretion, in turn, increases the expression of the PAF-R. In a mixed culture model of rat and human MCs, it was demonstrated that PAF was able to upregulate ECM secretion (23); a corresponding increase in Fn and Col IV was additionally observed in this model (24). To support this observation, it was confirmed in the present study that pretreatment of the HMCs with HG
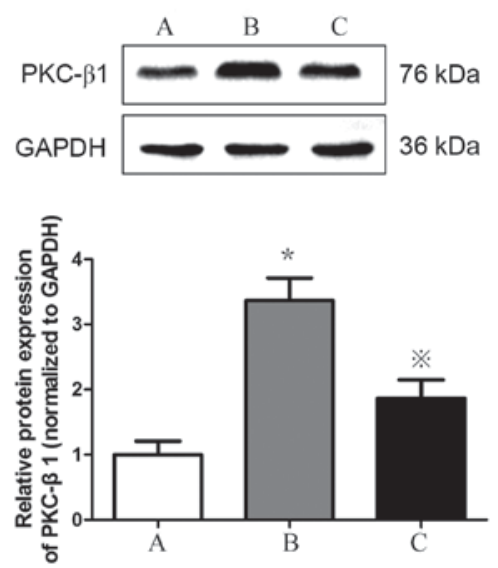

Figure 8 . PKC- $\beta 1$ protein expression in human mesangial cells under various treatment conditions. Protein expression levels were determined by western blotting, with GAPDH used as a loading control. Group A, control; Group B, HG+LPC; Group C, HG+LPC+atorvastatin. Data represents the mean \pm standard error of three independent experiments. $\mathrm{P}<0.05$ vs. group $\mathrm{A}$, ${ }^{*} \mathrm{P}<0.05$ vs. group B. PKC- $\beta 1$, protein kinase $\mathrm{C}-\beta 1$; HG, high glucose; LPC, lysophosphatidylcholine.
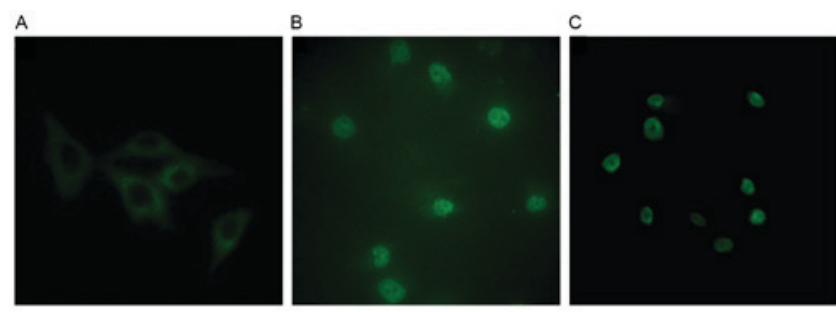

Figure 9. Immunocytofluorescent analysis of PKC- $\beta 1$ localization in human mesangial cells under various treatment conditions. PKC- $\beta 1$ was detected by immunocytofluorescence and visualized by confocal microscopy. Magnification, x400. Group A, control; Group B, HG+LPC; Group C, $\mathrm{HG}+\mathrm{LPC}+$ atorvastatin. $\mathrm{PKC}-\beta 1$, protein kinase $\mathrm{C}-\beta 1$; HG, high glucose; LPC, lysophosphatidylcholine.

and LPC significantly increased Col IV and Fn via the induction of PAF.

Inflammatory factors promote the expression of TGF- $\beta 1$ by activating the PKC-dependent pathway; this stimulates the synthesis of Fn (16). In line with this statement, a rise in PAF activity in the cells exposed to HG+LPC was observed in the present study, which was concomitant with an increase in Fn, Col IV and PKC- $\beta 1$. PAF has detrimental effects in $\mathrm{MCs}$, and this may be through the activation of the PKC- $\beta 1$ signaling pathway, which leads to increased expression of ECM proteins (16). It has been previously reported that HG may activate the PKC- $\beta 1$ pathway and promote the secretion of TGF- $\beta 1$ in MCs. TGF- $\beta 1$ may further stimulate the synthesis of collagen III and IV, Fn and other ECM components (15). Consistent with these findings, the present study demonstrated that an increase in PAF expression in cells exposed to $\mathrm{HG}+\mathrm{LPC}$ was associated with increased levels of PKC- $\beta 1$ and TGF- $\beta 1$. This finding may indicate that PAF induces a molecular cascade that activates PKC- $\beta 1$, leading to ECM accumulation and glomerular sclerosis (21).

Statins have been widely used as lipid-lowering drugs to exert a protective effect on endotheliocytes. Statins reduce cardiovascular morbidity and mortality in patients 
Table V. Mean fluorescence intensity of PKC- $\beta 1$ in human mesangial cells under various treatment conditions.

\begin{tabular}{lc} 
Group & Mean fluorescence inten \\
\hline Control & $11.80 \pm 2.57$ \\
HG+LPC & $48.92 \pm 7.70^{\mathrm{a}}$ \\
HG+LPC+atorvastatin & $18.53 \pm 3.74^{\mathrm{b}}$
\end{tabular}

${ }^{\mathrm{a}} \mathrm{P}<0.05$ vs. control group; ${ }^{\mathrm{b}} \mathrm{P}<0.05$ vs. HG+LPC group. Each group was cultured for $24 \mathrm{~h}$ and the experiment was repeated three times. PKC- $\beta 1$, protein kinase C- $\beta 1$; HG, high glucose; LPC, lysophosphatidylcholine.

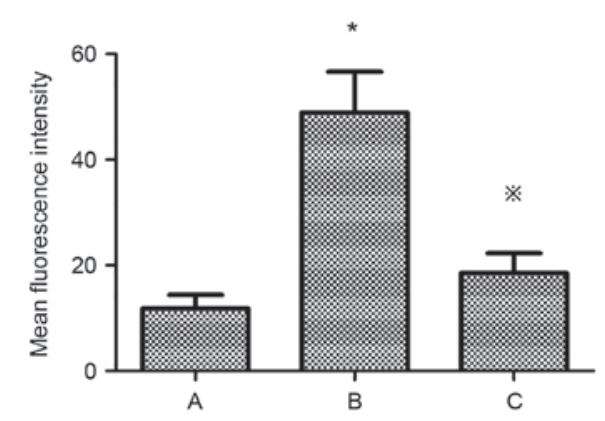

Figure 10. Mean fluorescence intensity of PKC $\beta 1$ in human mesangial cells under various treatment conditions. Group A, control $(5.5 \mathrm{mmol} / 1$ D-glucose); Group B, HG+LPC group (30 mmol/1 D-glucose+20 mg/l LPC); Group C, atorvastatin group (30 mmol/1 D-glucose+20 mg/1 LPC+10 $\mu \mathrm{mol} / 1$ atorvastatin). Data represents the mean \pm standard error of three independent experiments. ${ }^{*} \mathrm{P}<0.05$ vs. group $\mathrm{A},{ }^{*} \mathrm{P}<0.05$ vs. group $\mathrm{B}$. $\mathrm{PKC}-\beta 1$, protein kinase C- $\beta 1$; HG, high glucose; LPC, lysophosphatidylcholine.

with end-stage renal disease (25). This effect of statins may be due to their lipid-lowering effects, in addition to their pleiotropic effects, including the ability to promote endothelial repair, and reduce inflammation and oxidative stress (26). Atorvastatin inhibits the HG-induced secretion of Col IV and Fn, mesangial matrix deposition and mesangial cell proliferation $(27,28)$. Atorvastatin has been reported to have anti-fibrotic effects in chronic kidney disease (9). Essentially, atorvastatin has the ability to reduce glomerular mesangial ECM deposition, and thus delay the progression of glomerular sclerosis (29). A previous study demonstrated that statins inhibit the production of PAF, and this action may be through the inhibition of TGF- $\beta 1$ and reactive oxygen species as well as the expression of other cytokines, in addition to mothers against decapentaplegic homolog protein expression in glomerular MCs, thus inhibiting Fn and Col IV secretion (9). A recent report observed that statins may suppress PAF production (30), and they may therefore effectively treat cardiovascular diseases, and conditions including diabetes (31) and DN (32). The present study revealed that atorvastatin reduced the PAF content in MCs in a HG and LPC environment. This may be associated with the upregulation of PAF-acetylhydrolase activity (33), leading to an increase in PAF degradation and thus reducing the renal protective effect of ECM secretion in the culture model. The present study additionally demonstrated that the expression of the PAF-R gene in the HMCs in the atorvastatin-pretreated group was significantly decreased compared with the HG and LPC group. This suggested that atorvastatin may inhibit the expression of the PAF-R gene in HMCs induced by $\mathrm{HG}$ and LPC. The expression of the PAF-R gene in MCs is associated with nuclear factor $-\kappa \mathrm{B}(\mathrm{NF}-\kappa \mathrm{B})$ activity. $\mathrm{HG}$ and LPC may activate the PKC-NF- $\kappa \mathrm{B}$ pathway in MCs, which subsequently increases the transcription of the PAF-R gene (34). However, the present study identified that when the PAF-R gene was significantly increased, PKC- $\beta 1$ and TGF- $\beta 1$ were increased. Therefore, it may be hypothesized that atorvastatin may inhibit the expression of the PAF-R gene in HG and LPC induced HMCs by inhibiting the activation of TGF- $\beta 1$, and inhibiting the PKC pathway. However, the specific mechanism remains unclear and requires further investigation.

In the present study, the expression of PKC- $\beta 1$ mRNA and protein in HMCs pretreated with atorvastatin was significantly lower compared with groups treated with HG and LPC alone. Immunofluorescence indicated that the expression of PKC- $\beta 1$ in the cytoplasm and nucleus was additionally reduced, suggesting that atorvastatin may inhibit the activation of the PKC pathway under the conditions of HG and LPC. Simvastatin inhibits inflammatory and oxidative stress by inhibiting the activation of the PKC pathway, thus exerting a protective effect in patients with chronic kidney disease (35). Atorvastatin may inhibit the expression of TGF- $\beta 1$, which may alleviate the local inflammatory reaction of the kidney (36). In the present study, suppression of PKC- $\beta 1$ signaling by atorvastatin is partly responsible for the reduced levels of PAF and ECM. These results all suggest that atorvastatin may alter the activation of the PKC- $\beta 1 / \mathrm{TGF}-\beta 1$ pathway to reduce ECM secretion in HMCs stimulated by HG and LPC, although the specific mechanism remains unclear and further research is required.

In conclusion, the results of the present study suggested that atorvastatin may reduce the secretion of ECM proteins (Fn and Col IV) by inhibiting the secretion of PAF, the expression of PAF-R, and the activation of the PKC- $\beta 1 / \mathrm{TGF}-\beta 1$ signaling pathway in HMCs under HG and LPC conditions. Additionally, these findings revealed that atorvastatin may delay glomerular fibrosis by inhibiting the PKC- $\beta 1 /$ TGF- $\beta 1$ signaling pathway in HMCs. This mechanism may contribute to the efficiency of atorvastatin for the treatment of DN.

\section{Acknowledgements}

The authors gratefully acknowledge Professor Sun Zilin from the Zhongda Hospital Affiliated with Southeast University (Nangjing, China), for the donation of immortalized human mesangial cells. The authors would also like to thank the Science and Research Center, Guilin Medical University (Guilin, China) for their technical support.

\section{Funding}

The present study was supported by the National Natural Science Foundation of China. Grant: Research on the relationship between insulin resistance of podocytes in diabetic neuropathy (grant no. 81560148). 


\section{Availability of data and materials}

The datasets used and/or analyzed during the current study are available from the corresponding author on reasonable request.

\section{Authors' contributions}

SXZ designed the study. YHX and XYH performed the experiments, and YHX was the major contributor in the writing of the manuscript. QH and FY analyzed the data. All authors read and approved the final manuscript.

\section{Ethics approval and consent to participate}

Not applicable.

\section{Consent for publication}

Not applicable.

\section{Competing interests}

The authors declare that they have no competing interests.

\section{References}

1. Shao Y, Lv C, Wu C, Zhou Y and Wang Q: Mir-217 promotes inflammation and fibrosis in high glucose cultured rat glomerular mesangial cells via Sirt1/HIF-1 $\alpha$ signaling pathway. Diabetes Metab Res Rev 32: 534-543, 2016.

2. Chang ZL, Beezhold DH, Personius CD and Shen ZL: Fibronectin cell-binding domain triggered transmembrane signal transduction in human monocytes. J Leukoc Biol 53: 79-85, 1993.

3. Liu Y, Wang Z, Yin W, Li Q, Cai M, Zhang C, Xiao J, $\mathrm{Hou} \mathrm{H}, \mathrm{Li} \mathrm{H}$ and $\mathrm{Zu} \mathrm{X}$ : Severe insulin resistance and moderate glomerulosclerosis in a minipig model induced by high-fat/high-sucrose/high-cholesterol diet. Exp Anim 56: 11-20, 2007.

4. Yiu WH, Lin M and Tang SC: Toll-like receptor activation: From renal inflammation to fibrosis. Kidney Int Suppl (2011) 4: 20-25, 2014.

5. Fragopoulou E, Iatrou C, Antonopoulou S, Ruan XZ, Fernando RL, Powis SH, Moorhead JF and Varghese Z: Platelet-activating factor (PAF) increase intracellular lipid accumulation by increasing both LDL and scavenger receptors in human mesangial cells. J Lab Clin Med 147: 281-289, 2006.

6. Koya D, Jirousek MR, Lin YW, Ishii H, Kuboki K and King GL: Characterization of protein kinase $\mathrm{C}$ beta isoform activation on the gene expression of transforming growth factor-beta, extracellular matrix components, and prostanoids in the glomeruli of diabetic rats. J Clin Invest 100: 115-126, 1997.

7. Banach M, Dinca M, Ursoniu S, Serban MC, Howard G, Mikhailidis DP, Nicholls S, Lip GY, Glasser S, Martin SS, et al: A PRISMA-compliant systematic review and meta-analysis of randomized controlled trials investigating the effects of statin therapy on plasma lipid concentrations in HIV-infected patients. Pharmacol Res 111: 343-356, 2016.

8. Zhao L, Zhao Q, Zhou Y, Zhao Y and Wan Q: Atorvastatin may correct dyslipidemia in adult patients at risk for Alzheimer's disease through an anti-inflammatory pathway. CNS Neurol Disord Drug Targets 15: 80-85, 2016.

9. Song CY, Kim BC and Lee HS: Lovastatin inhibits oxidized low-density lipoprotein-induced plasminogen activator inhibitor and transforming growth factor-beta1 expression via a decrease in Ras/extracellular signal-regulated kinase activity in mesangial cells. Transl Res 151: 27-35, 2008

10. Kom GD, Schwedhelm E, Maas R, Schneider L, Benndorf R and Böger RH: Impact of atorvastatin treatment on platelet-activating factor acetylhydrolase and $15-\mathrm{F}$ (2trans)-isoprostane in hypercholesterolaemic patients. Br J Clin Pharmacol 63: 672-679, 2007.
11. Zhou SX, Lei MX, Zhao JJ and Chen HL: The study of the effects of platelet activating factor (PAF) on the relation between the endothelial cell and mesangial cells exposed to high glucose and high lysophosphatidylcholine. Chin J Diabetes 18: 591-593, 2010 (In Chinese).

12. Sraer JD, Delarue F, Hagege J, Feunteun J, Pinet F, Nguyen G and Rondeau E: Stable cell lines of T-SV40 immortalized human glomerular mesangial cells. Kidney Int 49: 267-270, 1996.

13. Livak KJ and Schmittgen TD: Analysis of relative gene expression data using real-time quantitative PCR and the 2(-Delta Delta C(T)) method. Methods 25: 402-408, 2001.

14. Zhu D, Qian F, Wu Y, Jones DS, Rowe C, Narum DL, Duffy P, Miller LH and Saul A: Determination of protein concentration for protein-protein conjugates using ultraviolet absorption. J Immunol Methods 387: 317-321, 2013.

15. Meier M, Park JK, Overheu D, Kirsch T, Lindschau C, Gueler F, Leitges M, Menne J and Haller H: Deletion of protein kinase C-beta isoform in vivo reduces renal hypertrophy but not albuminuria in the streptozotocin-induced diabetic mouse model. Diabetes 56: 346-354, 2007.

16. Tahara A, Tsukada J, Tomura Y, Yatsu T and Shibasaki M: Vasopressin increases type IV collagen production through the induction of transforming growth factor-beta secretion in rat mesangial cells. Pharmacol Res 57: 142-150, 2008.

17. Davignon J: Emphasis on pleiotropic effects, a new paradigm shift? Coron Artery Dis 15: 223-225, 2004.

18. Alfaro V: Role of histamine and platelet-activating factor in allergic rhinitis. J Physiol Biochem 60: 101-111, 2004.

19. Tsoupras AB, Fragopoulou E, Nomikos T, Iatrou C, Antonopoulou S and Demopoulos CA: Characterization of the de novo biosynthetic enzyme of platelet activating factor, DDT-insensitive cholinephosphotransferase, of human mesangial cells. Mediators Inflamm 2007: 27683, 2007.

20. Reznichenko A and Korstanje R: The role of platelet-activating factor in mesangial pathophysiology. Am J Pathol 185: 888-896, 2015.

21. Honda ZI, Ishii S and Shimizu T: Platelet-activating factor receptor. J Biochem 131: 773-779, 2002.

22. Asano KK, Taniguchi SS, Nakao AA, Watanabe TT and Kurokawa KK: Distribution of platelet activating factor receptor mRNA along the rat nephron segments. Biochem Biophys Res Commun 225: 352-357, 1996

23. Ruiz-Ortega M, Bustos C, Plaza JJ and Egido J: Overexpression of extracellular matrix proteins in renal tubulointerstitial cells by platelet-activating-factor stimulation. Nephrol Dial Transplant 13: 886-892, 1998.

24. Ruiz-Ortega M, Largo R, Bustos C, Gómez-Garre D and Egido J: Platelet-activating factor stimulates gene expression and synthesis of matrix proteins in cultured rat and human mesangial cells: Role of TGF-beta. J Am Soc Nephrol 8: 1266-1275, 1997 .

25. Kopecky C, Genser B, Drechsler C, Krane V, Kaltenecker CC, Hengstschläger M, März W, Wanner C, Säemann MD and Weichhart T: Quantification of HDL proteins, cardiac events, and mortality in patients with type 2 diabetes on hemodialysis. Clin J Am Soc Nephrol 10: 224-231, 2015.

26. Tremoulet AH: The role of statins in inflammatory vasculitides. Autoimmunity 48: 177-180, 2015.

27. Kolavennu V, Zeng L, Peng H, Wang Y and Danesh FR: Targeting of RhoA/ROCK signaling ameliorates progression of diabetic nephropathy independent of glucose control. Diabetes 57: 714-723, 2008.

28. Mooradian AD and Haas M: Statins ameliorate glomerular permeability changes in streptozotocin-induced diabetic rats. Am J Ther 14: 41-45, 2007.

29. Song Y, Li C and Cai L: Fluvastatin prevents nephropathy likely through suppression of connective tissue growth factor-mediated extracellular matrix accumulation. Exp Mol Pathol 76: 66-75, 2004.

30. Jaikumkao K, Pongchaidecha A, Chattipakorn N, Chatsudthipong V, Promsan S, Arjinajarn P and Lungkaphin A: Atorvastatin improves renal organic anion transporter 3 and renal function in gentamicin-induced nephrotoxicity in rats. Exp Physiol 101: 743-753, 2016.

31. Pahan K: Lipid-lowering drugs. Cell Mol Life Sci 63: 1165-1178, 2006.

32. Tsoupras AB, Iatrou C, Frangia $C$ and Demopoulos CA: The implication of platelet activating factor in cancer growth and metastasis: Potent beneficial role of PAF-inhibitors and antioxidants. Infect Disord Drug Targets 9: 390-399, 2009. 
33. Noto H, Hara M, Karasawa K, Iso-O N, Satoh H, Togo M, Hashimoto Y, Yamada Y, Kosaka T, Kawamura M, et al: Human plasma platelet activating factor acetylhydrolase binds to all them urine lipoproteins, conferring protection again stoxidatives tress. Arterioscler Thromb Vasc Biol 23: 829-835, 2003.

34. Park CW, Kim JH, Lee JH, Kim YS, Ahn HJ, Shin YS, Kim SY, Choi EJ, Chang YS and Bang BK: High glucose-induced intercellular adhesion molecule-1(ICAM-1) expression through an osmotic effect in rat mesangial cells is PKC-NF-kappa B-dependent. Diabetologia 43: 1544-1553, 2000.

35. Zhang F, Sun D, Chen J, Guan N, Huo X and Xi H: Simvastatin attenuates angiotensin II-induced inflammation and oxidative stress in human mesangial cells. Mol Med Rep 11: 1246-1251, 2015.
36. Vincent JL, Spapen H, Bakker J, Webster NR and Curtis L: Phase II multicenter clinical study of the platelet-activating factor receptor antagonist BB-882 in the treatment of sepsis. Crit Care Med 28: 638-642, 2000

(i)(9) This work is licensed under a Creative Commons Attribution-NonCommercial-NoDerivatives 4.0 International (CC BY-NC-ND 4.0) License. 